\title{
Chapter 1 \\ Evidence-Based Analysis of Issues in Environment, Energy, and Disaster Risks with CGE Models: An Introduction to Part I
}

\author{
John R. Madden
}

\begin{abstract}
This chapter demonstrates the capabilities of CGE modeling as a tool for the numerical assessment of the likely consequences for economies of a number of severe risks. These relate to the environment, particularly climate change, energy, and disastrous events, such as a pandemic. These were issues of particular concern to Yuzuru Miyata who developed CGE models to examine them. The discussion of the Part I chapters draws out how carefully undertaken CGE analysis can provide vital numerical evidence to inform policy-makers. Particular attention is paid to two key features of the chapters: customization of general-purpose CGE models for capturing essential features of the issue under examination; and a careful examination of simulation results with explanations provided in terms of the key model mechanisms driving them.
\end{abstract}

Keywords Computable general equilibrium · Environment · Climate change · Energy policy $\cdot$ Risk analysis $\cdot$ Pandemics

\subsection{Overview}

At the beginning of the 2020s, following the warmest decade for mean global temperatures on record, there are heightened fears of potentially catastrophic outcomes from anthropogenic climate change. While most countries ratified the Paris Agreement with its goal of holding the average global temperature increase to well below $2{ }^{\circ} \mathrm{C}$ above pre-industrial levels, it is uncertain whether this target will

\footnotetext{
J. R. Madden $(\bowtie)$

Centre of Policy Studies, Victoria University, Melbourne, Australia

e-mail: john.madden@vu.edu.au
} 
actually be achieved. ${ }^{1}$ In many countries, the politics surrounding climate change has constrained mitigation action.

A major component of the policy debate on climate change surrounds the cost of greenhouse gas reduction actions, a question on which there has been a good deal of public disagreement in many countries. It is of clear importance that the public debate should be informed by scrupulous analysis, which provides sound numerical estimates of the overall costs of greenhouse gases mitigation, and of inaction, and of the spread of those costs over counties, regions, and specific groups. The latter is important, since it is those who feel that they might bear a disproportionate share of the costs of mitigation (e.g., owners of fossil fuel assets, workers in high-emitting energy industries) who are probably most likely to oppose climate action.

Since global warming began to emerge as a major issue at the end of the 1980s, computable general equilibrium (CGE) has been deemed to be a method well suited to undertaking numerical analysis of climate change policies. ${ }^{2}$ This view is founded on CGE's strong theoretical foundations combined with its extensive empirical data. These qualities are particularly important in climate change analyses, which are regularly concerned with examining future scenarios that are outside the range of previous experience. Central to CGE's strengths is its inclusion of resource constraints and price-responsive behavior. CGE's capacity for detailed treatment of many industries, occupations, regions, and household types allows the identification of winners and losers from policy changes and other economic shocks. CGE projections of the ramifications of climate change scenarios for all sectors of the economy can help move the public debate away from special pleading arguments and provide an evidence base to underpin compensation to groups that are likely to be harmed by policies aimed at reducing the likelihood of catastrophic climate change. ${ }^{3}$

The power of CGE modeling for economic analysis of potential natural and manmade disasters, both at local and at global levels, was well known to Yuzuru Miyata to whom this book is dedicated. He was a leading developer of CGE models in Japan and used his models to examine a range of economic issues facing Japan and

\footnotetext{
${ }^{1}$ The Agreement also stated that a target of no more than a $1.5^{\circ} \mathrm{C}$ should be pursued. However, the UK Met Office's forecasts suggest a $10 \%$ chance that the average mean global temperature may temporarily break the $1.5 \%$ temperature increase for a single year of the 2020 s between 2020 and 2025 (Vaughan 2020).

${ }^{2}$ Examples of earlier CGE modeling of climate change mitigation policies are: Marks et al. (1990) for Australia, Burniaux et al. (1992) for Europe, and Madden (1991) for an Australian region. Since then CGE has become a standard method for analyzing the economic effects of climate change, mitigation policies, and related energy issues. Among numerous examples in the literature, a few examples are: McKibbin et al. (1999), Adams (2007), Adams and Parmenter (2013), Jorgenson et al. (2013) and McKibbin and Wilcoxen (2013).

${ }^{3}$ It is worth noting in this regard that CGE modeling for Australia has consistently shown the overall cost of substantial climate action is unlikely to be large. For instance, modeling by Philip Adams indicates that achieving Australia's 2030 Paris target by phasing in a domestic emissions trading scheme would reduce the nation's GDP by around 2\% (Adams and Parmenter 2013). This is small in comparison to overall economic growth over a 20 -year phase in period.
} 
other Asian countries. A key focus of his CGE research was on environmental issues and disastrous events. For instance, in the 1990s Miyata developed a dynamic CGE model to examine waste and recycling issues within an economy-wide framework (Miyata 1995, 1997; Miyata and Pang 2000). Of particular relevance to this book is his CGE modeling of the local effects of a carbon tax (Miyata et al. 2013). The economic effects of other types of potential disasters formed another major research interest for Miyata who developed a dynamic spatial CGE model in order to examine them. Applications of the model included simulating the economic effects of a major earthquake in the Tokai region, an earthquake-prone area facing the possibility of a high magnitude occurrence (Shibusawa et al. 2009; Shibusawa and Miyata 2011).

The following eight chapters of Part I of this book comprise contributions by leading international CGE researchers reporting on model applications that are wellmatched with Professor Miyata's interest in examining environmental economic issues and the economic consequences of potentially disastrous events. The major emphasis of Part I is on climate change and associated issues relating to energy, resource depletion, agricultural productivity, and food security. The final chapter in Part I (Chap. 9), however, relates to a risk of a potentially disastrous event, namely the threat of a highly virulent pathogen, Ebola, being imported into a developing country in the Asia-Pacific. With the increase in global travel in recent decades, there is a heightened risk of new (or novel strains of) infectious diseases turning into pandemics. As well as the human cost, the Ebola study shows that an outbreak can have very severe economic effects, particularly where a country lacks preparedness in the form of sufficient surveillance. Restrictions on trade and travel that may be used in an attempt to contain an outbreak-such as those put in place at the time of writing (February 2020) to combat the spread of the novel coronavirus from its epicenter in China's Hubei province-can also have profound economic effects. Dixon et al. (2011) reveal this in their CGE study of a hypothetical US border closure, which highlights the importance of selectivity in the coverage of the bans and strategic stockpiles of certain commodities.

The Part I chapters demonstrate the power of CGE models to capture the key features of policy questions and provide an evidence-based platform for informing policy formation and public debates. The models employed in the various chapters can be described as large-scale general purpose CGE models, which contain a detailed treatment of the behavior of numerous economic agents and the linkages between them. ${ }^{4}$ A feature of many of the chapters is that, where a CGE model might not fully capture some attribute of particular importance to a specific issue, new application-specific theory and/or data is introduced. The size and complexity of CGE models mean that considerable emphasis must be placed on explaining simulation results in terms of the model's theory and data, model closure, and the

\footnotetext{
${ }^{4}$ Our attention in Part I is on the application of CGE models to issues of risk management, particularly the risks posed by climate change. This is just one of the wide range of policy relevant research areas in which CGE models, initially developed to examine mainly tax and trade issues, are now constantly employed.
} 
shocks imposed. A characteristic of the chapters here is the discussion of results, using sound techniques for uncovering the major model mechanisms driving the results. Such result interpretation is necessary to ensure that simulation results are internally valid and hinge on credible theory and data. It also provides the basis for clear explanations and justifications of the findings presented to policy makers and others (see Dixon and Rimmer 2013; Giesecke and Madden 2013).

Part I has a strong focus on the Asia-Pacific, with chapters on two of the three largest Asian economies, China and India (Asia's second largest economy, Japan, is the focus of Part II). Other Asia-Pacific countries studied in Part I are Vietnam, and the small nations of Brunei, Timor-Leste, and the Pacific nation of Fiji. Two chapters report modeling of Brazil, a near neighbor of countries on South America's Pacific coast, and one that shares similar problems, such as deforestation, with a number of Asian nations. As a point of comparison, a chapter with a UK application is also included.

\subsection{CGE Analysis of Environmental and Energy Issues in the Asian Region}

In Chap. 2, Peter Dixon, Maureen Rimmer, Rajesh Chadha, Devender Pratap, and Anjali Tandon demonstrate the power of CGE modeling in providing the evidence base for policy advice. They examine the efficacy of India's very large agricultural subsidies, a third of which are on fertilizer and electricity inputs, which have detrimental environmental effects. The authors customize their model by giving a regional dimension to the agricultural industries attracting most of the subsidies, thus capturing interregional differences in input mixes and, for electricity, interregional differences in subsidy rates. They conduct subsidy removal simulations and find that the agricultural subsidies involve a substantial deadweight loss, most of it associated with the fertilizer and electricity subsidies. An interesting result is that these two subsidies actually lower farm income, as opposed to the other agricultural subsidies which meet the aim of raising it. The authors demonstrate that a change in the agricultural subsidy mix that involved phasing out of the fertilizer and electricity subsidies would raise real farm income and would have a small positive impact on welfare. The chapter provides an excellent illustration of a convincing explanation of results through back-of-the-envelope (BOTE) techniques. For instance, geometrical BOTE techniques are used to form an initial estimate of welfare effects and regression analysis is then used to examine the extent to which agricultural industry results are the outcome of an expected range of drivers (changes in subsidy rates). While the initial BOTE estimates explain much of the model results, the authors proceed to discover the reasons behind the gaps between the BOTE results and the actual simulation results. This uncovers mechanisms contained in the CGE model, but not in the initial BOTE. This allows the BOTE explanation to be improved, for example, by adding extra explanatory variables to a regression equation. Being able to fully explain a simulation's results in this way greatly adds to the credibility of the authors' simulation results. 
Energy and greenhouse emissions in China are the subject of Chap. 3 by Philip Adams and Xiujian Peng. They conduct forecasts for the 2017-2030 period in order to examine the effects on China's growth, energy efficiency, and greenhouse gas emissions targets of alternative policies. The forecasts are carried out with an extended version of the recursive dynamic CGE model, CHINAGEM. The authors' enhancement of CHINAGEM, involved the introduction of detailed modeling of the energy industry, with separate treatment of six substitutable energy types. Domestic gas is separated into conventional and unconventional producers. China is currently experiencing a transition from investment- to services-led growth. Adams and Peng show that by 2030, compared to a business-as-usual forecast, an expected accelerating transition (Scenario 1) will boost China's growth and there would be a slight reduction in greenhouse emissions due to a cleaner energy mix. A significant reduction in greenhouse gas emissions would be achieved under Scenario 2 (a cap on coal consumption), but there would also be a small negative effect on GDP. In the case of Scenario 3 (increasing unconventional gas production), there would be a slight worsening of the level of emissions, but very little (negative) effects on the 2030 Chinese economy. Adams and Peng find that under a well-designed policy that appropriately combined the three policy scenarios, achievement of China's 2030 targets should be attainable.

Another aspect of the energy question is examined by Irene Yap, Philip Adams, and Janine Dixon in Chap. 4 for the small nation of Brunei. The authors use a recursive dynamic CGE model, BRUGEM, to consider Brunei's economic future as its oil and gas resources, on which the nation is heavily dependent, become depleted. They carry out a historical simulation to update their database and then conduct forecast simulations to 2040. Under their baseline forecast (which assumes a continuation of the current level of attempts at diversification), GDP is projected to fall substantially as the hydrocarbon resources become depleted, with a cumulative GDP decrease by 2040 of just over $40 \%$ from its 2011 level. The authors consider whether a range of possible productivity improving initiatives might temper this outcome. They simulate an all-factor-saving productivity improvement designed to add one percentage point to annual GDP growth. This would very substantially alleviate the 2040 cumulative decline in GDP. However, they find that achieving such a GDP effect would require a large productivity improvement $(2.5 \%$ per annum). An important finding is that in order to maintain employment at baseline levels, the real wage would need to fall from its baseline level by $86 \%$. This unexpected finding demonstrates how a CGE model can reveal mechanisms within an economy that might otherwise not be thought of. The explanation for what is not normally the outcome of a productivity improvement stems from some unusual features of the Brunei economy. The economy is dominated by the capital-intensive oil and gas industries, which accounts for $80 \%$ of the nation's capital, and the laborintensive government sector, which employs half the workforce and whose output is assumed fixed for the productivity improvement simulation. With the oil and gas sectors disappearing, there are limited possibilities for the remaining sectors to absorb displaced government workers without a substantial fall in the real wage. 
Climate change poses a variety of serious risks for Vietnam. In Chap. 5, Nhi Tran, Huong Pham, and James Giesecke examine the effects of climate change on 6 crops within Vietnam's agricultural sector. Six climate change scenarios are simulated for the 20 years to 2030 with a multiregional dynamic CGE model of Vietnam: three different climate change scenarios, modeled either with or without adaptation (e.g., increased agricultural extension). Results presented are for deviations from a no-climate change baseline simulation. The authors introduce a multi-household income/expenditure extension into their Vietnamese CGE model in order to capture distributional effects. While their model is for a single country, the authors take into account climate change effects on agriculture globally by applying appropriate import and export price shocks to capture changes to the world prices of rice and maize resulting from climate change. With climate change reducing crop yields and harvest areas, the simulations result in negative deviations in Vietnam's GDP and (public and private) consumption. There is considerable variation in regional effects, but with the exception of the Southeast region, all regions are negatively affected. The worst affected region, the Central Highlands that is intensive in the production of coffee, is projected to experience a GDP reduction by 2030 of $20-25 \%$ if no extra adaptation measures are put in place. The negative effects are mainly felt by the agriculture sector, with other sectors experience relatively small, and generally negative effects. All urban and regional households are negatively affected, with inequality between income groups increasing mainly due to higher food prices having a greater impact on poorer households. The simulated adaptation measures are of a size to substantially ameliorate these effects. However, for the two climate change scenarios based on the more pessimistic projected temperature increases, virtually all reported variables remain negatively affected.

\subsection{Modeling Climate Change Issues in Brazil}

Climate change is expected to have substantial effects on human migration. In Chap. 6, Joaquim Ferreira and Mark Horridge investigate the consequence of climateinduced effects on Brazilian agriculture for interregional migration patterns. Their analysis is carried out using the multiregional TERM-MIG model of Brazil, which incorporates an interregional migration module that computes gross bilateral flows of workers between the model's 13 regions as a function of historical migration patterns and relative regional real wages. Using IPCC 2020 worst case and 2070 best case emission scenarios, coupled with agricultural productivity and land loss estimates from the literature, Ferreira and Horridge simulate the impact of climate change on 7 agricultural crops over 55 years to 2070. Annual shocks are estimated for the years 2015-2025 based on the 2020 scenario, while for the latter period the annual shocks are based on the 2070 forecast, in line with their assumption that adaptation measures will be in place during these years. At the national level economic activity progressively falls below the baseline forecast, particularly in the earlier years before adaptation measures are assumed to be put in place. By 2070, 
the cumulative effect of the climate change scenarios causes real GDP to be almost $0.8 \%$ below its baseline forecast, with the real wage down by just over $1 \%$. The effects on the 7 climate-affected crops show them falling into two groups, with 5 of the crops in a band having declines of $1.4 \%-5.8 \%$ below baseline by 2070 , but Soybeans and Coffee down by around 40\%. Regional outcomes are largely affected by the importance of negatively affected crops and the severity of climate change effects in the different regions. The authors find that the climate change scenarios would reverse current migration patterns, re-establishing some of the more traditional patterns of a few decades ago, with net migration again flowing from agricultural-oriented regions to richer states in the southeast. The decline in agriculture would also see some migration toward the Amazon. TERM-MIG incorporates occupational detail, leading to the revelation that less skilled workers would constitute the larger portion of migrants, threatening to worsen the large slums in the southeast.

Brazil's commitment to the Paris Agreement on Climate Change is substantially based on reducing deforestation. One idea for achieving this is an increase in livestock productivity to release pasture land for crops, easing deforestation pressures. However, livestock price reductions consequent on the productivity improvement would also increase demand for livestock products, leading to an increase in emissions from a larger herd. In Chap. 7, Leandro Stocco, Joaquim Ferreira, and Mark Horridge examine the question of which of these two opposite effects on greenhouse gas emissions might dominate with the aid of TERM-BR, a recursive dynamic multiregional CGE model of Brazil. The model contains two enhancements that enable their study: a land-use module and a greenhouse emissions module. The former module determines land-use transitions, based on historical patterns (revealed by satellite imagery) and relative prices of agricultural products. The latter module computes emissions from two sources: firstly fuel use and activity of productive sectors; and secondly land-use changes, which captures changes in carbon sinks via deforestation/reforestation. The authors make an important innovation in the emissions module so that it takes into account the effects on "activity" emissions of changes in rates of carbon sequestration in soils. With the use of municipal data and satellite imagery, the authors compute the gap between actual and potential livestock productivity, the latter being based on the most productive Brazilian municipalities, adjusted by land aptitude for pasture. They then simulate a 50\% reduction in the yield gap and find that this does have an overall positive effect on the economy and does reduce emissions. Taking account of the improved carbon storage in soils associated with pasture improvement is crucial to the emissions reduction result. It turns out that emissions from the increase in herd size do outweigh emission reductions from reduced deforestation, but taking into account increased carbon sequestration more than offsets this, leading to an overall emissions reduction. 


\subsection{Fiscal Policy and Its Effects on Meeting Energy and $\mathrm{CO}_{2}$ Emissions Targets in the United Kingdom}

The next chapter returns to the questions of emissions and energy, which were the subject of analysis for Asia's most populated country in Chap. 3, and one of its least populated in Chap. 4. The Chap. 8 analysis is for the United Kingdom, one of the foremost countries in the regional science community outside the Asia-Pacific for CGE analysis since the 1980s, principally due to the work of the University of Strathclyde team. In Chap. 8, Andrew Ross, Grant Allan, Gioele Figus, Peter McGregor, Graeme Roy, Kim Swales, and Karen Turner consider the interaction between: (1) a fiscal policy that alters the output mix between the private sector and the lower energy using/ $\mathrm{CO}_{2}$ emitting public sector, and (2) the energy system and overall $\mathrm{CO}_{2}$ emissions. Their analysis is carried out with their UK CGE model, UKENVI, custom built to encapsulate the interdependence between the energy system and the rest of the economy. The model is used to conduct a set of fiscal policy experiments under a range of long-run labor market environments. The labor market is central to their analysis and they initially provide a detailed partial equilibrium analysis of the likely effect of the alternative labor market environments on their results via several diagrams. Their preferred labor market alternative is that of a bargained real wage (BRW), for which they provide supporting evidence of it being the most likely to reflect reality. Other alternatives are for the polar opposites of either exogenous employment or a fixed real wage, the former often employed in CGE modeling, while the latter is sometimes considered to reflect past periods of "real wage resistance" in the United Kingdom. The authors' interest in these alternatives is partly to consider alternative views of how the UK labor market works and partly to benchmark opposite end limits in order to test the sensitivity of results to different labor market assumptions. Simulations are carried out for unfunded increases in government expenditure and for changes in income tax rates to alter debt levels. Their results show GDP to be considerably more sensitive to tax changes than government expenditure changes under the BRW alternative. A balanced budget simulation is then undertaken for a $5 \%$ tax increase under the alternative labor market assumptions. Only under the probably unlikely case of a fixed real wage in pre-tax terms is a reduction in emissions accompanied by a long-term increase in GDP. The more elastic are labor supply curves the greater the emissions reduction, but the greater too are the negative effects on GDP. With exogenous employment, GDP declines only slightly due to a compositional move toward a slightly lower capital intensity. The authors also simulate the case of social wage bargaining involving some type of agreement between government and trade unions to modify wage demands in exchange for the benefits received from greater government expenditure. Under this labor market alternative, a rightward shift in the labor supply curve accompanies an increase in government expenditure. This results in a balanced budget increase in government expenditure reducing emissions and increasing employment with only a trivial fall in GDP. The authors note that wage 
bargaining in the United Kingdom is probably not centralized enough for a social wage bargain. The modeling does suggest, however, the importance of coordination of fiscal and energy policies.

\subsection{Modeling Catastrophic Disasters: The Case of a Potential Ebola Outbreak in Small Asia-Pacific Nations}

The subject of the last chapter of Part I relates to another major research interest of Professor Miyata, the economic impact of disastrous events. The hypothetical disastrous event considered in Chap. 9 by Nic Geard, James Giesecke, John Madden, Emma McBryde, Rob Moss, and Nhi Tran is a pandemic occurring in developing countries in the Asia-Pacific. Specifically, they considered the economic consequences that might have eventuated if the 2014 West African Ebola pandemic had reached the small nations of Timor-Leste and Fiji. Simulations were carried out for a number of alternative intervention strategies. Pandemics differ in their health effects, and the authors, therefore, developed a stochastic disease transmission model which they tailored to the key characteristics of Ebola. This allowed them to estimate the economic shocks arising from an outbreak in a particular country, prior to applying these shocks to a quarterly version of the GTAP model, GTAPQ. Some of the key characteristics of Ebola captured by the disease model were: long incubation period, not airborne, very high fatality rate, and continued infectiousness after death. For each intervention strategy, the stochastic disease model was run 500 times, providing a range of outcomes for disease states of the population, varying from outbreaks fading out to them becoming uncontrollable. Typical daily country outcomes for controlled and uncontrolled outbreaks under 5 alternative intervention strategies were converted to quarterly disease state results, which in turn were used in the estimation of GTAP-Q shocks to country-specific health costs and labor productivity during the outbreak, and permanent reductions in each country's population and labor force due to mortality. Estimations for behavioral consequences-severe reductions in international tourism and crowd avoidance-formed further shocks. The GTAP-Q simulations revealed very large economic costs associated with uncontrolled Ebola outbreaks, and in the case of Fiji, which has a significant tourism sector, considerable economic costs for controlled outbreaks. The authors find that purely reactive strategies had virtually no effect on preventing uncontrolled outbreaks, but preemptive strategies substantially reduced the proportion of uncontrolled outbreaks, and in turn the likely economic and social costs. 


\section{References}

Adams PD (2007) Insurance against catastrophic climate change: how much will an emissions trading scheme cost Australia? Aust Econ Rev 40(4):432-452

Adams PD, Parmenter BR (2013) Computable general equilibrium modeling of environmental issues in Australia: economic impacts of an emissions trading scheme. In: Dixon PB, Jorgenson D (eds) Handbook of computable general equilibrium modeling, vol 1A. Elsevier, Amsterdam

Burniaux J, Martin JP, Nicoletti G, Martins JO (1992) GREEN a multi-sector, multi-region general equilibrium model for quantifying the costs of curbing $\mathrm{CO}_{2}$ emissions: a technical manual. OECD Economics Department working papers no. 116, Paris. https://doi.org/10.1787/ 744101452772

Dixon PB, Rimmer MT (2013) Validation in CGE modeling, chapter 19. In: Dixon PB, Jorgenson DW (eds) Handbook of computable general equilibrium modeling. Elsevier, Amsterdam

Dixon PB, Giesecke JA, Rimmer MT, Rose A (2011) The economic costs to the U.S. of closing its borders: a CGE analysis. Defence Peace Econ 22(1):85-97

Giesecke JA, Madden JR (2013) Evidence-based regional economic policy analysis: the role of CGE modelling. Camb J Reg Econ Soc 6(2):285-301

Jorgenson DW, Goettle RJ, Ho MS, Wilcoxen PJ (2013) Energy, the environment and US economic growth, chapter 8. In: Dixon PB, Jorgenson DW (eds) Handbook of computable general equilibrium modeling. Elsevier, Amsterdam

Madden JR (1991) Regional economic impacts of reducing $\mathrm{CO}_{2}$ emissions. In: Gordon MT, Gordon BLJ (eds), Regional modelling and regional planning (Proceedings of the Conference at University of Newcastle, September 20-21 1990), Institute of Industrial Conference Series No. 18, University of Newcastle, Newcastle, pp 119-129. https://catalog.princeton.edu/catalog/ SCSB-8520985

Marks RE, Swan PL, McLennan P, Schodde R, Dixon PB, Johnson DT (1990) The cost of Australian carbon dioxide abatement. Energy J 12(2):135-152

McKibbin WJ, Wilcoxen PJ (2013) A global approach to energy and the environment: the Gcubed model, chapter 15. In: Dixon PB, Jorgenson DW (eds) Handbook of computable general equilibrium modeling. Elsevier, Amsterdam

McKibbin WJ, Shackelton R, Wilcoxen PJ (1999) What to expect from an international system of tradable permits for carbon emissions. Resour Energy Econ 21(3-4):319-346

Miyata Y (1995) A general equilibrium analysis of the waste-economic system - a CGE modeling approach. Infrastructure Plan Rev 12:259-270

Miyata Y (1997) An intertemporal general equilibrium analysis of the waste-economic system. Infrastructure Plan Rev 14:421-432

Miyata Y, Pang X (2000) Economic and material accounting matrix and its application to computable general equilibrium analysis of plastics recycling. Stud Reg Sci 31(1):195-219

Miyata Y, Wahyuni A, Shibusawa H (2013) Economic analysis of the impact of carbon tax on the economy of Makassar City, Indonesia. Reg Sci Inq J 5(2):15-31

Shibusawa H, Miyata Y (2011) Evaluating the dynamic and spatial economic impacts of an earthquake: a CGE application to Japan. Reg Sci Inq 3(2):13-25

Shibusawa H, Yamaguchi M, Miyata Y (2009) Evaluating the impacts of a disaster in the Tokai region of Japan: a dynamic spatial CGE model approach. Stud Reg Sci 39(3):539-551

Vaughan A (2020, 8 February) Climate forecast says we may break the record for warmest year by 2025. New scientist, p 15 